\title{
Retraction Note: EANM Abstracts 2013
}

John Smith

Published online: 5 February 2014

(C) Springer-Verlag Berlin Heidelberg 2014

Retraction to: Eur J Nucl Med Mol Imaging

DOI 10.1007/s00259-013-2535-3

Abstract P469 withdrawn at author's request due to inadvertent miscalculation.

The online version of the original article can be found at http://dx.doi.org/ 10.1007/s00259-013-2535-3.

J. Smith $(\bowtie)$

EANM, Vienna, Austria

e-mail: office@eanm.org 